\title{
The Impact of Galileo Open Service on the Location Based Services Markets: A Review on the Cost Structure and the Potential Revenue Streams
}

A. Basiri, E. S. Lohan, T. Moore

\begin{abstract}
Many Location Based Services (LBS), such as navigation and tracking services, are using Global Satellite-based Navigation Systems (GNSS). GNSS is the most widely used positioning solution for LBS outdoors, therefore any improvement in the quality of GNSS positioning services will directly improve the quality of LBS and therefore it will generate more revenue and attract more users. One of the upcoming satellite navigation systems is Galileo, which is being deployed by the European Union (EU). Beside all political motivations behind Galileo, the availability of more satellites in view and a more accurate, reliable and continuous positioning service are some of the technological motivations of having yet another of GNSS on sky. Such improvement in positioning service and, as a result, in LBS applications will develop the market and attract more users. However, due to long delays, current powerful competitors which are making the GNSS market increasingly crowded, and also the cost of Galileo being covered by EU taxpayers only, there is a question if another of GNSS is really required and it is able to return all its cost in near future. This chapter assesses the financial aspects of Galileo at the time of writing the book, including increasing costs and impact of losing some parts of market and also its potential revenue and the economic impact of positioning and timing service improvement by Galileo, and finally the impact of Galileo on future markets of LBS is estimated.
\end{abstract}

Anahid Basiri

The Nottingham Geospatial Institute, The University of Nottingham, UK,

e-mail: anahid.basiri@nottingham.ac.uk

Elena Simona Lohan

Tampere University of Technology, Korkeakoulunkatu 10, 33720 Tampere, Finland,

e-mail: nunzia.ferrara@tut.fi

Terry Moore

The Nottingham Geospatial Institute, The University of Nottingham, UK,

e-mail: terry.moore@nottingham.ac.uk 


\section{Introduction}

Location Based Services generate the biggest portion of revenue within all GNSS applications; more than half of all GNSS revenue is from LBS and it is predicted to get $62 \%$ of the whole global GNSS market revenue by 2020 [8]. Mobile phones and smartphones, tablets, portable computers, and fitness devices are some of platforms to receive/run location-based applications and services. There are more than 2.5 Billion mobile devices with the Global Positioning System (GPS) capabilities globally [17]. However, the wide range of advantages of receiving multi-GNSS signals has made manufacturers and also users willing to produce/have multi-GNSS enabled devices (i.e. equipped with multi-GNSS antennas, the front-ends, baseband processing, and navigation solution software). This has resulted in a competition between GNSS systems to be the second in line, following GPS, in the market. On the other hand, many users all around the world have got used to the free-ofcharge GPS signals. The success of GPS in generating a worldwide size market may put the financial success of another GNSS system under question; Does the GNSS market really needs another satellite navigation system besides the current two fully functional ones, namely GPS and GLObal NAvigation Satellite System (GLONASS)? Can another GPS-like system be financially successful and generate reasonable amount of revenue while free-of-charge GPS signals are available globally? Can another GNSS can have a significant impact on the LBS markets and/or improve quality of such services? The European Union has been developing and deploying a civil-based GNSS, however the Galileo programme has already faced several delays, which resulted in the increase of cost and also possibly losing some parts of the global markets, such as potentially big market in China and India as they are now deploying their own Satellite Navigation System (the Indian system is regional), the GNSS market is becoming more and more crowded, as more satellite navigation systems are being developed and deployed within Galileo's delays. On the other hand, beside all the political motivations, the Galileo program is based also on many technological and social justifications [13]. EU views Galileo as a technologically complement/backup to GPS not a rival [4]; the 2004 agreement between EU and the USA regarding compatibility and interoperability of GPS and Galileo makes it easier to benefit from availability of more satellites in view. Many LBS applications can benefit from availability of more satellites that may result in better continuity and accuracy of positioning services. This can help emergency, security and safety related applications, which directly increase the quality of life of people. Also more accurate and continuous navigation services, such as in car navigation services, can help more people to save more fuel and time. In addition, being the only civil-based GNSS, as all the others are military-controlled systems, puts Galileo in a more reliable position for many other critical and sensitive applications such as timing for bank transactions, oil industry-related applications, etc., as many countries can rely on American or Russian military-controlled systems now. These are only a few examples of future applications where Galileo can play an important role and therefore there is a global market to be shared with Galileo. In addition to the complementary role of Galileo to GPS, Galileo will be a complete stand-alone 
GNSS and if it only target people within Europe as its future users, i.e. mandated by the European Commission (EC), the annual core revenue from device shipment and services in a few years can be almost equal to the whole cost of development, validation and deployment of the whole system of Galileo. Galileo also plans to deliver a Commercial Service (CS) possibly at a fee for professional users, which may change the landscape of the revenues that Galileo could generate. The Galileo CS foresees to offer precise point positioning and code encryption services for authentication, complementing the open service authentication which would be provided for free. However, as the Commercial Service specifications have not formally been endorsed by the Galileo programme at the time being, they are not quantified in this chapter.

This chapter reviews the impact of Galileo, the European GNSS, on the LBS market by considering both positive and also sceptical economic views on Galileo. The chapter studies the cost structure of Galileo and then estimates economic impact of it on the global LBS market and also its own generated revenue by 2022. This chapter will assess the financial cost and potential market size and its impact on LBS, as the largest revenue generator segment of GNSS applications, when Galileo finally will get to its fully-functionalities. Next section reviews the cost structure, the questionable features and the scepticism regarding the financial aspects of Galileo system. Then in section three the potential markets and opportunities, unique features and enabling services of Galileo will be discussed. Also some suggestions and recommendations are made.

\section{Galileo Cost Structure and Scepticisms}

The necessity of having another GNSS system, in addition to GPS, has been under question; many people all around the world, including the EU taxpayers who have been paying for full costs of Galileo, and have got used to free-of-charge GPS signals, may ask whether launching and maintaining another GPS-like system is financially justifiable. This section reviews views against and for the financial aspects of Galileo including its investments and cost structure and potential revenue streams when it gets to its full functionality level. The total cost of Galileo, including development and validation ( $€ 2.4$ billion), deployment ( $€ 3.4$ billion) and also 20 years of support, operating costs (20*€800 million p.a.) and deployment phase of The European Geostationary Navigation Overlay Service (EGNOS) (€1.1 billion) has been reported as $€ 23$ billion. However, these figures and numbers and all cost estimations have been subjected to many changes since 2000 when the initial estimates from EC were released [3]. For example deployment cost was initially estimated about 2.15 billion euro while in EC report in 2013 it was more than double folded. Table 1 shows the detailed cost estimations so far. Facing delays in different phases of the project, public-private partnership funding negotiations and scheme transformation [12], delays in plans and launches and most fundamentally time-consuming 
process of reaching agreements by all EU member states are some of the reasons of increasing Galileo costs. In below some of these reasons are discussed.

One of the fundamental reasons of increasing the cost of Galileo has been the EU decision-making process in general. This decision making us influenced by a large number of member states (27 EU countries) in comparison with other systems which are being run by military authorities of only one country. Consequently, the management and decision-making process for Galileo are much longer than for other similar systems. This has already resulted in several delays, change in funding schemes and even changes in technical plans for Galileo. Reaching an agreement has been a quite time-consuming process as there are more negotiations and discussions on different member states' concerns and issues. For example, member states had long discussions and negotiations over where the system's activity centre (including ground infrastructure and headquarters) would be located. Obviously for other GNSS systems, which are run by military/ air force authorities of one country, this was not an issue [20]. Such negotiations have resulted in delays and changes, and this also increased the Galileo deployment cost. One of the best examples of this can be having reached the agreement on financial supports of Galileo, which leaded the whole project to a pause and consequently added $€ 103$ million to the project cost; Between July 2005 and December 2005, discussions and negotiations between the member states and the private investors regarding an agreement on how to financially move forward, led the whole project to a six-month of pause with no progress. According to the European Court of Auditors this period of doing nothing but negotiations, by itself, added $€ 103$ million to the cost of the project, i.e. additional $€ 17$ million per month to the cost of the project.

The GNSS markets are becoming more and more crowded as other satellite navigation systems, such as Russian GLONASS, Chinese BeiDou 2, and also some regional systems including Indian Regional Navigation Satellite System (IRNSS) and Japanese Quasi-Zenith Satellite System (QZSS), are being or have been developed and deployed. While other GNSS systems are making the market crowded, Galileo is still facing some delays. In addition to having more competitors in the GNSS market, Galileo has lost some parts of its to-would-be potential markets, such as quite big markets in China and India.

The continuous delays in Galileo deployment has arisen questions regarding its future markets and profitability of Galileo services when it gets to its full functionality level. In addition to have more market competitors, the delays in the Galileo programs have damaged its management robustness, reputation and expectations regarding economic and also technical sustainability. These damages and threats of having more intimidating market competitors may become more and more serious issues if Galileo faces more delays and unfortunately some these issues, such as losing the market in some regions where a well-established competitor of Galileo is in control of a full-functional system, which could hardly be compensated.

There are many who have had deep reservations about the cost of Galileo from the outset - and, in particular, the uncertainties that exist about what the precise end-cost will be. Beside the increasing cost of Galileo, there are some scepticisms regarding future market of Galileo. On the other hand, there are many potential areas 
from which Galileo can generate revenue or have indirect impacts. Next section studies Galileo future market and also discusses its potential markets, the revenue streams, and the impact of Galileo on the LBS market.

\section{Galileo Potential Revenue Streams and Opportunities}

Developing future markets for Galileo encounters some challenges and scepticisms and enjoys some potentials and opportunities. As the GNSS market gets more and more crowded, Galileo cannot play a major role in the big markets of GNSS in China, Russia and India, however being the only GNSS system run and controlled by non-military sector makes it easier for other countries to trust [15]. Being the only civil-based system can potentially make Galileo as the third or even the second GNSS system being used by almost all countries as there is a trust issue due to current political situation between the key GNSS players, i.e. the US, Russia and China [2]. In this regard, the interoperability, compatibility with GPS based on official agreements with the US can significantly enhance Galileo's role as the second system in the GNSS market in Europe, the US, Africa and Middle East, and as the third system in Russia and far east. For the summary of Galileo strength, weakness, opportunities and threat, see SWOT analysis below.

The GNSS market share in the US, Europe, Africa and Middle East and Asia (excluding China) generates more than $80 \%$ of the whole GNSS revenue (see figure 2) and being the second in such a big and well-established market, i.e. with 60 billion euro of core revenue and 200 billion euro of enabled revenue, could still be a good target for Galileo [10].

The agreement between the US and Europe recognises that civil GPS and Galileo with compatible and interoperable radio frequency at the user level, can increase the number of satellites visible from any location on the Earth and aid the accessibility to navigation signals for civil users worldwide [4]. In addition, due to political situation and sanctions against Russia, if continued, Galileo can potentially come even as the second system to support by American and European receiver manufacturers [13]. The Europe and US based manufacturers are 91 percent of all LBS chipset producers globally, by the number and also by the revenue [8]. In addition, no particular import-export control policy in the EU makes it easy for the Galileo-enabled devices to be shipped. The global annual GNSS core revenue (such as shipment of GNSS receivers and devices) is currently $€ 60$ billion [8] and is expected to have a market size of $€ 110$ billion in 2022 [8]. Even ignoring the growth as the result of the agreement between the US and EU regarding GPS and Galileo signal compatibility, and also unfairly assuming that only EU citizens will only use all the Galileo devices, then giving EU population respect to the rest of the world, it is estimated that Galileo can have an annual market of $€ 5.3$ billion. This is only the direct GNSS market revenue and all other enabled, indirect and long-term revenues have not been taken into account yet. The global annual revenue from enabled services and products of GNSS is currently more than $€ 180$ billion and this will get up to $€ 240$ billion 


\begin{tabular}{|c|}
\hline $\begin{array}{l}\text { Strengths } \\
\text { - Having higher positional and temporal } \\
\text { accuracy } \\
\text { - Being the only civil-based GNSS } \\
\text { Having a Europe-size default market } \\
\text { (mandate) } \\
\text { - Interoperability, compatibility based on } \\
\text { official agreements with GPS (with } 100 \% \text { of } \\
\text { GNSS market capability) } \\
\text { - Having very broad range of well-developed } \\
\text { potential applications, which are currently } \\
\text { based on available GNSS (potentially similar } \\
\text { selling points) } \\
\text { Potentially secure and robust market at least } \\
\text { in Europe } \\
\text { No particular import-export control of Galileo- } \\
\text { enabled devices }\end{array}$ \\
\hline
\end{tabular}

\begin{tabular}{|l|}
\hline Opportunities \\
- \\
Political and military management of other \\
competitors (as all are military based, its \\
harder to be trusted and also reach \\
agreements) \\
- $\quad$ Minimum Europe-wide market size (mandate) \\
- $\quad$ barriers for Galileo-enabled devices \\
applications \\
Well-developed augmentation system \\
\end{tabular}

\section{Weaknesses \\ - Lack of obvious competitive strength \\ - Having encountered delays which have damage its reliability in management \\ - Facing delays resulted in having more competitors, loosing a big part of its potential markets in China and India \\ - Multi-national management procedure which makes the decision making process time- taking \\ - Having collapsed PPP has arisen scepticisms regarding financial benefits and returns (even between EU states) \\ - Application predictability \\ - Need of having plan transparency}

\section{Threats}

- GPS technical threats (jamming, spoofing) remain Galileo's too.

- No obvious market push/demand

- Facing several delays results in increase in cost and loosing some big markets (specially in China, India)

- Upcoming/already developed technologies (e.g. BLE, 4G, Wi-Fi 5G) can be used for many LBS applications (as the major GNSS market segment)

- Having GNSS market more and more crowded

- Having well-established competitors with mostly free of charge services

Fig. 1 Galileo: SWOT analysis

by 2022 [8]. Again if, unfairly, assume that Galileo enabled services market is only limited to EU, then Galileo-enabled services and products will have a Europe-wide market of about $€ 30$ billion. In addition to political situation, which can bring a potential opportunity for Galileo to be used in many countries and for many sensitive and commercial applications [2], there is another unique feature of Galileo, which can help Galileo to establish its role in the GNSS markets; the signal authentication can be another motivation for receiver manufacturers to produce Galileo-enabled chipsets. Although according to the current service layers of Galileo [9], i.e. Open Service, Search and Rescue and Public Regulated Service, authenticated signals will not available for open service, it would be possible for Galileo to make most of such unique and enabling service if it became available for everyone. There are several revenue streams and financial justifications, particularly targeting a replacement for mandating Galileo, behind this suggestion. The authors believe that providing the authenticated signal of Galileo for free would be a good opportunity to attract a huge 


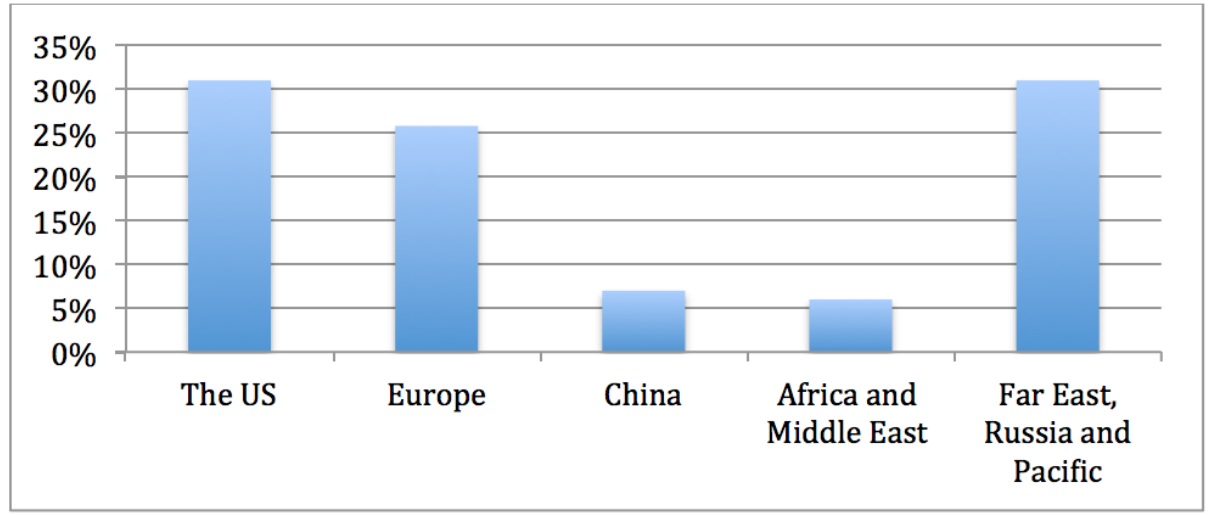

Fig. 2 The GNSS market share by Region [8]

market within the EU and even beyond the EU borders [19]. This can be done even without mandating Galileo, which might be legally and politically challenging task. According to market studies, $6 \%-7 \%$ of the value of all the finished goods and services produced within EU borders in 2013 (GDP), which is estimated about $€ 800$ billion, currently relies on satellite navigation signals provided by the GPS [18]. This dependency equals about $€ 850$ billion (European Commission report, 2014) (Based on 6.5\% of the EU28 GDP of $€ 13.075 .000$ million in 2013.). A disruption of the GPS signal would therefore have a major impact on the European economy. The following range of services rely on GNSS: Location-Based Services (LBS) are a class of information services that use location/geographic data -the LBS market and number of users and devices has faced enormous growth over the last years. Its revenues are estimated to $€ 735$ million in 2013 , expecting to grow up to $€ 2.3$ billion in 2018.

The road segment consists of many different applications, such as Advanced Driver Assistance Systems (ADAS), Road User Charging (RUC), Pay-per-use insurance (PPUI) and road traffic monitoring. It is a market in transition; over 50 million units are in use within the European Union [8] and its relative share in the GNSS market is expected to continuously grow. The navigation systems used by the aviation sector demand the highest robustness and integrity. The use of GNSS within all aviation segments is expected to increase over the next decade reaching a penetration of over $90 \%$ by 2022 . GNSS devices in the rail segment are used by major train companies to track all of their trains. The use of GNSS is expected to grow significantly within the next years. This is a good sign for European manufactures, because the market is dominated by Europe when it comes to the shipment of Rail GNSS devices, more than 5,000 units in 2012 [8]. One of the first adopters was the maritime segment. Global shipment of GNSS devices within this market hovers around 100,000 in 2012, just over 25\% of Maritime devices serviced the European market. The economic importance of GNSS to agriculture is modest yet advancing. 
With technological adoption established at a high level in Western Europe major growth is foreseen in Central and Eastern Europe.

European Space Agency (ESA) expects the value of businesses relying on satellite navigation to grow by roughly $11 \%$ a year, and to be worth $€ 244$ billion by 2020 [8]. This dependency is increasing since more web and mobile transactions, services and applications have become commonly available. This dependency is the case for almost all the regions and countries. Due to sensitivity of the applications and services, such as bank transaction synchronisations, and also relatively large market relying on potentially vulnerable GPS signals, there is a high demand to have a reliable (back up) system. Providing authenticated signals by Galileo for free (i.e. as a part of the Open Service of the only civil based GNSS) would be a great motivation for many countries to switch to and rely on Galileo. This large market may not bring many revenue streams directly but indirectly makes many systems and services use Galileo signals and build the trust on Galileo system for other sort of services, which may bring more money.

In addition to enabling services, there are some direct revenues; many sensitive services, such timing and synchronisation, aviation and maritime may require to receive authenticated signals and this only be provided by Galileo. Although timing and synchronisation, aviation and maritime applications are less than $3 \%$ of the global GNSS market share [8], about $30 \%$ of component manufacturers in their value chain are based in Europe. The authentication of the signal and also having access to local, Europe-based, companies make it possible to make these valuable and sensitive segments of the GNSS markets dominantly Galileo-based.

Galileo is the only civil-based satellite navigation system, therefore it would be more reliable for many countries to use Galileo's signals for their sensitive and critical applications such as power grid synchronisation, electronic trading and banking, mobile phone network, air traffic management. Galileo will always be controlled under non-military sectors [7]; this will bring secure signals, which are required for such critical application. In this regard, there would be a welcoming market for Galileo. In addition to business side, Europe should not rely on GPS signals anymore due to sensitivity of such applications, political issues and also economic reasons [20],[11]; EU annual GDP, which relies in GPS signals in one year, is enough for whole Galileo system deployment. Therefore Galileo is a politically and financially justifiable system as it can bring bigger markets and also it is in line with EU security policies [11].

European Commission officials have publicly and recently stated that they are considering how to stimulate Galileo use; in particular through regulatory measures requiring that navigation equipment be installed on aircrafts, cars and other platforms. However, according to a US government representative at the international satnav forum (GPS World, 2015) such mandating use of specific GNSS services for applications such as emergency calling, road tolling and LBS applications could violate the terms of World Trade Organisation (WTO) agreement, including promoting open market access and the agreement on Technical Barriers to Trade (TBT), and the general agreement on Trade in Services (GATS), that many nations including all 
six satellite navigation service providers (i.e. US, EU, China, Russia, India, Japan) have signed [6], [13].

In order to avoid such conflicts and agreement violations, it is recommended to discuss and assign technology-neutral, platform-based standards [6]. For example the US E911 rules specify positioning accuracy requirements while allowing to choose the best technical solutions accordingly.

As it shown in table 1 and explained previously, Galileo's cost has been increasing due to changes in plans, delays and management issues. This has caused scepticisms regarding investments and future turnover.

One of the most important reasons of having increasing cost is the collapse of the Private-Public Partnership (PPP) in 2007, see table 1. In addition to cost increase, having investment structure changed raises some questions about stability and profitability of Galileo when it gets to the full functionality level [12]; If would-to-be committed funding bodies and private investors doubted they can get back their investments why other shouldn't?

Looking at the GPS investment structure may help to answer this question. GPS was built at a considerable cost by the US taxpayers and the returns to the American economy have shown that such investments have been rapidly paid back, actually many times over. GPS market forecasted in the infancy years of GPS (1984-1988) barely got to one billion USD; in 2001 GPS market estimated to get 5.2 billion USD, this doubled in only four years [14]. Nowadays core revenue of GPS is more than 50 billion USD [4]. This can be considered as a good model for Galileo; if publicly funded GPS has repaid its debt to the US taxpayers even more than once, why Galileo cannot do so.

It has estimated that in 15 years after full functionality of Galileo, Galileo can pay back its debt to the public sector from revenues generated through the sale of guaranteed Galileo signal accuracy, mainly to governments. But most of these profits will be made toward the end of this period, this might be the justification why PPP had collapsed; private investors may need the return of their money directly and off course earlier than this time and more importantly due to repeating delays this time could postpone even more.

Off course, the same revenue stream and structure of GPS is not expected from Galileo due to having more crowded market competitors. Early GPS entrepreneurs are now dollar billionaires, but how much room is left in the GNSS market for others? More accurate timing results in more accurate and continuous positioning service. Galileo higher level of accuracy, better signal penetration, more satellite in view, continuity and other parameters of quality of the positioning service can contribute in many LBS applications, including navigation. Galileo is a fully standalone system however the market trends, applications requirements and freely available similar service (competitors) push it not be only used as a standalone system. Galileo better signal penetration, for indoor and urban canyon positioning, and Galileo signal compatibility and interoperability with GPS, will bring opportunity to have more satellites in view, can provide LBS users with more accurate and continuous positioning service, see figure 3 . It has been estimated that more accurate and continuous positioning services in conjunction with real time traffic data, only in car naviga- 


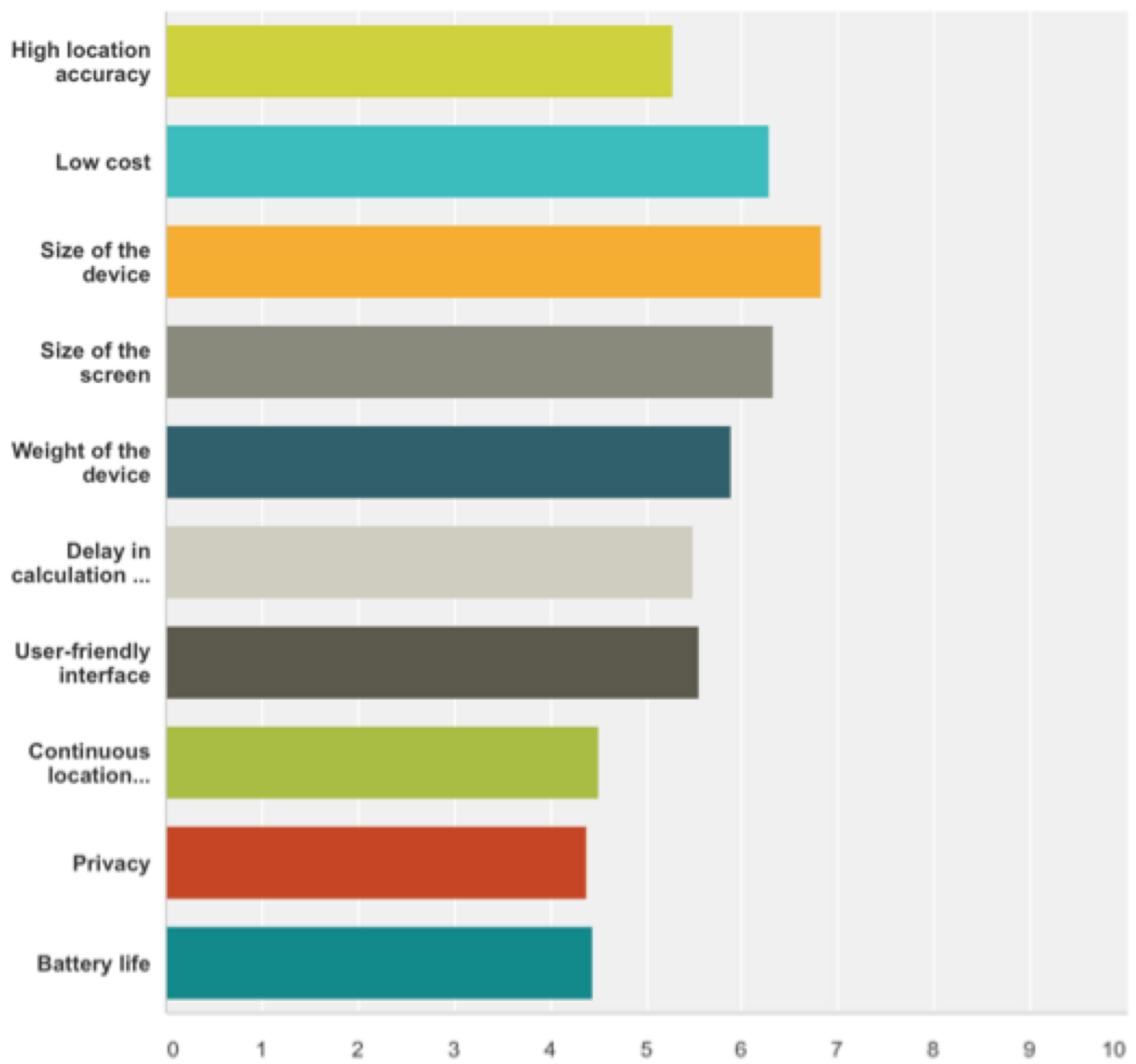

Fig. 3 Quality of LBS service/device from users' perspective (A conducted survey by the authors)

tion, may save up to 460 billion euro by 2020. McKinsey Global Institute (2011) estimated that people all around the world will save more than $€ 460$ Billion annually by saving in "time" and "fuel" by 2020 as a result of use of personal location data captured by either personal smartphones or In-Car navigation systems. One of the most obvious examples of this is time and fuel saving of avoiding congestions and suggestion of alternative routes. Galileo can definitely contribute in regards of more accurate and continuous positioning data capture, however this contribution will save more money rather than generate revenue. Just in Europe currently there 
are more than 500 million smartphones and tracking devices in Europe, which is more than $25 \%$ of global share.

Savings from less fuel consumption, and less time spent on travels can be beneficial for industry, although the economic contribution of Galileo is not as obvious as its direct revenue, or at least is not appreciated by investors in the same way. The contribution of Galileo in having less carbon dioxide due to less fuel consumption (which is due to more accurate and continuous car navigation services) would be quite significant as well. Considering all of savings from Galileo contribution in navigation, discussed above, Galileo can contribute about $25 \%$ of the whole $€ 460$ Billion, annually. This would be far more than its initial investments. However, this contribution is more in the form of savings rather than revenue. Another example of such savings and long-term returns is spill over effect; A research project by Oxford Economics shows that the technical advances that come about as a result of research and development investments in the space industry are transferred to firms in other sectors in the form of "spill-over" effect, which is surprisingly large; the social return of around $70 \%$ in long term is expected. If only development and deployment phases' costs ( $€ 2.4$ billion $+€ 3.4$ billion) are considered as R\&D investments, then an increase of $€ 4$ billion in long term in other sectors (such as health, transport, computer science) is expected. As it was shown by two simple examples, there are many applications, verticals and segments, which can benefit from Galileo services, however these benefits are not all in the form of revenue. They are also in forms of cost saving, and spill-over effects, which are not the most favourable form of revenue streams as return of the investment will be long-term or even it spills over in other sectors. So Galileo would be able to return its initial investments and even far more than that, however this returned money would go to the pocket of its "real" investors, i.e. EU taxpayers, in the form of savings. According to a recent study, this window of opportunity gives Galileo an estimated worldwide GNSS market size of 1800 million users in 2010 and 3600 million users in 2020 . Nevertheless, other studies support the case that further benefits will arise from route guidance, improved personal emergency, management of taxis and ambulances [16], less pollution by reduction of travel times and creation of 140000 jobs. An estimate of all benefits for the period 2000 to 2020 is illustrated below: Economic benefits of $€ 62000$ million Social benefits of $€ 12000$ million Total benefits of $€ 74000$ million The total investment cost for the Galileo operable system is some 2300 million Euros (EU MEMO-11-717). From 2008 onwards the annual cost will be around 220 million Euros including operations, maintenance and replenishment. The above-mentioned opportunities would be generated if there will be no more delays in deployment and maintenance of Galileo. This assumption is not too ambitious as the findings are now secured and secondly there will be no design-changing negotiations over the technical or financial aspects of the system. In addition, there is an essential need to promote Galileo service, unique features and advantages of using its signals. This should target almost all market chain and user types, including chipset manufacturers, devices and application platforms, app developers, stakeholders, map and other spatial content providers, policy makers and researchers. Also the relevant policies, legislations and standards, such as import-export control, positional requirements 
and policies regarding upcoming E112, outreach and public engagement policies and plans need to be promoted as soon as possible to ease the Galileo market penetration. These can be done by providing R\&D funding to research institutes and SMEs, having workshops, seminars, hackathons and conferences to make developers and researchers aware of the unique features and multi-GNSS capabilities of Galileo, legal aspect done through industry, public and academia engagement and outreach initiatives, research and development funding and grants, export promotion and facilitation policies.

\section{Conclusion}

The success of GPS in generating such a big worldwide market may sound intimidating to another similar GNSS system and financial justification of the new system might be criticised by many. This chapter reviewed the impacts of Galileo, the European GNSS, on LBS markets, the Galileo cost structure and potential threats and also its strength and opportunities to generate revenue for all EU tax payers, who have invested in Galileo. The chapter has comprehensively reviewed the financial aspects, costs, threats and weakness of Galileo, and then estimates its economic impacts, strength and opportunities particularly for LBS market when Galileo gets to its full functionality level. Having faced several delays in development and deployment phases, being run and managed by larger number decision makers, i.e. EU state members, increase in cost of the whole project and also change in the cost structure over last years, have risen some questions and concerns, such as joining a more crowded market as more satellite navigation systems are being deployed by other regions such as Russia, China, India and Japan. On the other hand, unique features of Galileo, such as authentication of signal, higher accuracy and signal penetration, and being the only civil-based GNSS bring several market opportunities that can only be provided by Galileo. In addition there are even more opportunities if Galileo could establish itself as a multi-GNSS system in combination with GPS and similar systems; Galileo full interoperability and compatibility with GPS, more satellites in view and politically stability of the system management (the only non-military based GNSS) can generate more possibilities and opportunities. This chapter made some suggestions and recommendations, based the reviewed market reports, research papers, conducted surveys, interviews and personal and experts opinion, on making most of Galileo's opportunities and opening new revenue streams in the GNSS markets. They include making authenticated signals free for all users to attract more enabling services and sensitive applications, providing funding and grants for R\&D projects, public engagements and outreach initiatives, export control facilitation, workshops and meeting to promote and advertise Galileo multi-GNSS potentials and unique features, having no more delays in deployment and maintenance phases and finally furthering the negotiations with other GNSS systems to make it as compatible as possible to establish its third or even second place in the GNSS market. 
Title Suppressed Due to Excessive Length

\section{References}

1. S Abbondanza and F Zwolska. Design of meo constellations for galileo: towards a "design to cost" approach. Acta Astronautica, 49(12):659-665, 2001.

2. Gloria Pirzio Ammassari and Maria Cristina Marchetti. Innovation process in the european union: The case of the galileo project. In European Socio-Economic Integration, pages 129146. Springer, 2013.

3. Javier Pérez Bartolomé, Xavier Maufroid, Ignacio Fernández Hernández, José A López Salcedo, and Gonzalo Seco Granados. Overview of galileo system. In GALILEO Positioning Technology, pages 9-33. Springer, 2015.

4. Scott W Beidleman. GPS versus Galileo: balancing for position in space. Lulu. com, 2012.

5. EC. http://ec.europa.eu/enterprise/policies/satnav/galileo/index ${ }_{e}$.htm, 2016.

6. Bastian Giegerich. Navigating differences: transatlantic negotiations over galileo. Cambridge Review of International Affairs, 20(3):491-508, 2007.

7. Michael P Gleason. Galileo: Power, pride, and profit. the relative influence of realist, ideational, and liberal factors on the galileo satellite program. Technical report, DTIC Document, 2009.

8. GNSS GSA. Market report, issue 4, 2015.

9. Guenter W Hein, Thomas Pany, et al. Architecture and signal design of the european satellite navigation system galileo-status dec. 2002. Positioning, 1(02), 2009.

10. Ignacio Fernández Hernández. Galileo receiver research in europe. In GALILEO Positioning Technology, pages 249-271. Springer, 2015.

11. Thomas Hoerber. Creating esa. In Yearbook on Space Policy 2014, pages 243-254. Springer, 2016.

12. Ewout KILLEMAES. Study of Public-Private Partnerships in the European Space Industry. PhD thesis, Faculty of Science, Universiteit Gent, 2012.

13. Dejian Kong. Shaping a uniform governance structure over global navigation satellite system (gnss): The way of risk management. Uniform Law Review-Revue de droit uniforme, page unw019, 2016.

14. Jacobson L. GNSS markets and Application, volume 2002.

15. Johan Lembke. The politics of galileo. Center for West European Studies Tel, 412:648-7405, 2001.

16. MEMO/11/717. Galileo will boost economy and make citizens' lives easier, 2016.

17. Pew Research. Location-based services, smartphone ownership 2013: Three-quarters of smartphone owners use location-based services, 2013.

18. Paul Stephenson. Talking space: The european commission's changing frames in defining galileo. Space Policy, 28(2):86-93, 2012.

19. P Walker, V Rijmen, I Fernandez-Hernandez, J Simón, D Calle, O Pozzobon, and G SecoGranados. Galileo open service authentication: A complete service design and provision analysis. In Proceedings of the 28 th International Technical Meeting of the Satellite Division of The Institute of Navigation (ION GNSS+ 2015), pages 3383-3396, 2015.

20. SHENG-CHIH WANG. Surviving the crises: The changing patterns of space cooperation among the united states, russia, europe, and china. 2010. 


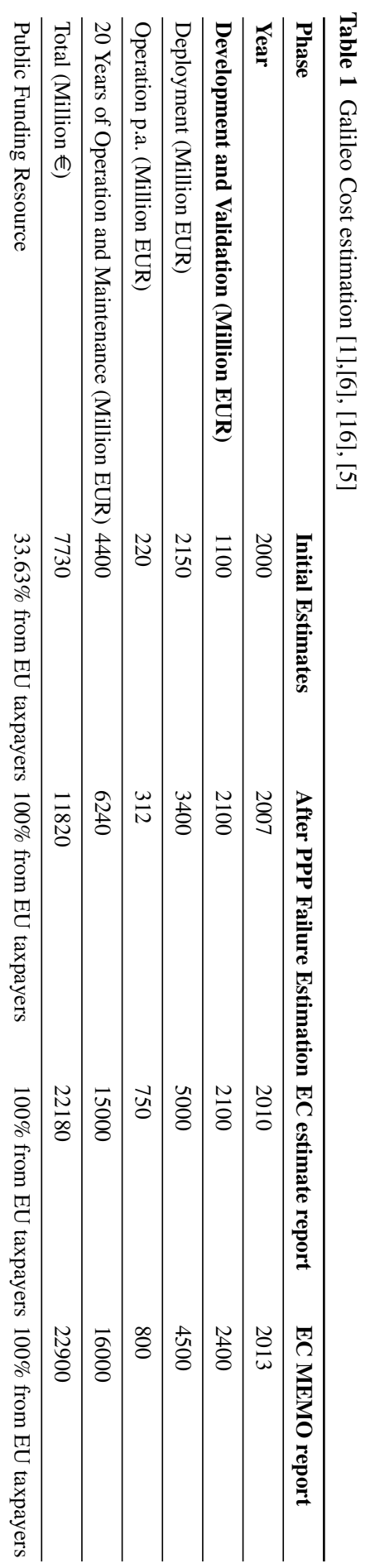

